University of Nebraska - Lincoln

DigitalCommons@University of Nebraska - Lincoln

\title{
Laboratory Comparison of Aedes Aegypti Attraction To Human Odors and To Synthetic Human Odor Compounds And Blends
}

\author{
Ulrich R. Bernier \\ University of Florida, ubernier@gainesville.usda.ufl.edu \\ Daniel L. Kline \\ United States Department of Agriculture \\ Sandra A. Allan \\ USDA-ARS, sandy.allan@ars.usda.gov \\ Donald R. Barnard \\ United States Department of Agriculture
}

Follow this and additional works at: https://digitalcommons.unl.edu/usdaarsfacpub

Part of the Agricultural Science Commons

\begin{abstract}
Bernier, Ulrich R.; Kline, Daniel L.; Allan, Sandra A.; and Barnard, Donald R., "Laboratory Comparison of Aedes Aegypti Attraction To Human Odors and To Synthetic Human Odor Compounds And Blends" (2007). Publications from USDA-ARS / UNL Faculty. 952.

https://digitalcommons.unl.edu/usdaarsfacpub/952
\end{abstract}

This Article is brought to you for free and open access by the U.S. Department of Agriculture: Agricultural Research Service, Lincoln, Nebraska at DigitalCommons@University of Nebraska - Lincoln. It has been accepted for inclusion in Publications from USDA-ARS / UNL Faculty by an authorized administrator of DigitalCommons@University of Nebraska - Lincoln. 


\title{
LABORATORY COMPARISON OF AEDES AEGYPTI ATTRACTION TO HUMAN ODORS AND TO SYNTHETIC HUMAN ODOR COMPOUNDS AND BLENDS ${ }^{1}$
}

\author{
ULRICH R. BERNIER, DANIEL L. KLINE, SANDRA A. ALLAN AND DONALD R. BARNARD \\ US Department of Agriculture, Agricultural Research Service, Center for Medical, Agricultural, and Veterinary \\ Entomology, 1600 SW 23rd Drive, Gainesville, FL 32608
}

\begin{abstract}
Chemical lures can enhance the ability of traps to collect mosquitoes, selectively target species for capture, and provide a realistic assessment of the species and host-equivalent numbers of mosquitoes present in the local area. One approach to the development of chemical lures is to manufacture blends that comprise odors released in human emanations. These blends need to be safe for use in the environment, desirable from an economic standpoint, and transportable to the field for use in traps. In this report, we compared the attraction of mosquitoes to various chemicals, blends, and odors from humans. Noncompetitive (single-treatment) bioassays established that some blends are equivalent or more attractive to Aedes aegypti than human odors. Competitive bioassays were conducted; these involved simultaneous comparison of 2 treatments: single compounds to binary blends; binary blends to a trinary blend of L-lactic acid, acetone, and dimethyl disulfide; and the trinary blend to human odors from 3 volunteers. The overall trend was that the trinary blend was more attractive than binary blends, and binary blends were more attractive than single compounds. However, human odors were still significantly more attractive than the trinary blend. Therefore, further modifications and refinements to blends will be needed to better compete against human odors.
\end{abstract}

KEY WORDS Attractants, kairomones, lactic acid, acetone, dimethyl disulfide

\section{INTRODUCTION}

Mosquito traps routinely employ carbon dioxide as a means to enhance the ability of the trap to collect mosquitoes; however, a drawback to the use of this compound in the field is that it can be burdensome and require frequent maintenance because it needs to be either delivered via a tank, delivered via dry ice, or produced by combustion. Therefore, discovery of suitable, environmentally safe, less-volatile replacements for $\mathrm{CO}_{2}$ would be highly beneficial in terms of portability and could potentially yield a reduction in the cost of baits. Additionally, selection of proper chemicals for baits can allow for selective capture of targeted insect species, e.g., blends of human-produced compounds to target anthropophilic mosquito species or blends of avian-produced compounds to target ornithophilic mosquito species. Beyond enhancement of trap collections and selective targeting, the use of these blends can provide increased accuracy in the assessment of species present in the local area for purposes of population surveillance and monitoring. One of the challenges of this research is to develop a blend of chemicals that produces high levels of mosquito attraction through designing blends that are comprised of odors released in human

${ }^{1}$ This paper reports the results of research only. Mention of a chemical compound does not constitute an endorsement for use by the US Department of Agriculture, nor does it imply registration under the Federal Insecticide, Fungicide, and Rodenticide Act as amended. skin emanations (Bernier et al. 2000). The shortcoming has been and continues to be that synthetic odor or extracted human component blends do not attract at a level comparable to human odors (Geier et al. 1999b).

Kairomones released from hosts are one type of cue used by mosquitoes to locate a blood meal (Takken 1991, Takken and Knols 1999). The yellow fever mosquito, Aedes aegypti (L.), is attracted to L-lactic acid in laboratory bioassays (Acree et al. 1968, Geier et al. 1996). This compound was shown to be an important component in the attraction of the malaria mosquito, Anopheles gambiae Giles (Dekker et al. 2002). Other compounds and combinations that have been shown to activate and attract mosquitoes in the laboratory and field are carbon dioxide (Gillies 1980); L-lactic acid and carbon dioxide (Smith et al. 1970, Geier et al. 1999a); 1-octen-3-ol and carbon dioxide (Takken and Kline 1989; Kline et al. 1990, 1991a, 1991b; Takken et al. 1997; Takken and Knols 1999); L-lactic acid and ammonia (Geier et al. 1999b); L-lactic acid, ammonia, and carboxylic acids (Bosch et al. 2000); and acetone, dimethyl disulfide, and dichloromethane, which attract synergistically when combined in a binary blend with lactic acid (Bernier et al. 2003). The ability of these latter blends to compete against a full bouquet of semiochemicals in the human odor profile has not been fully explored.

Semiochemical studies of human emanations have been conducted over the past decades for 
different purposes. In some cases, the emphasis has been to identify compounds produced by humans during space missions (Conkle et al. 1967, Ellin et al. 1974) or to discover chemical markers that factor in health, hygiene, and personal recognition (Sastry et al. 1980; Zeng et al. 1991, 1992; Wysocki and Preti 2000). In the area of mosquito host-seeking behavior, emphasis has been placed upon the chemical identification of human odors to uncover the constituents that produce odor-mediated attraction or attractioninhibition (anosmia) in anthropophilic mosquitoes, such as An. gambiae (Cork and Park 1996, Mukabana et al. 2004) and Ae. aegypti (Bernier et al. 2000, 2002; Bernier 2006). One of the sampling methods employed by Bernier et al. (1999, 2000) to identify human odors was based upon bioassays that showed that skin emanation residuum was attractive to mosquitoes when transferred to glass beads (Schreck et al. 1981) and that the difference was reproducible and quantifiable in bioassays (Schreck et al. 1990). These studies led to the identification of over 300 compounds; however, the factors that led to relative attraction among individuals was not discernible by differences in compounds or compound abundances seen via visual inspection of chromatograms from human individuals.

This paper is the successor to previous work with binary blends (Bernier et al. 2003) and reports further laboratory examination of the "USDA-blend" studies in the laboratory and field experiments of Williams et al. (2006). Herein, the attraction of female Ae. aegypti will be examined and compared using human odors, single compounds, and blends produced from these humanproduced compounds. Carbon dioxide is tested, as is the combination of L-lactic acid and $\mathrm{CO}_{2}$, because these serve as benchmarks to compare some of these promising binary odor blends. Our most potent attractive blend of L-lactic acid, acetone, and dimethyl disulfide (Bernier et al. 2001) is compared with the binary blends and, for the 1st time, against human odors from 3 volunteers in noncompetitive and competitive bioassays. This work also examines how well results of noncompetitive laboratory bioassays correlate to results from competitive bioassays conducted in our olfactometer (Posey et al. 1998).

\section{MATERIALS AND METHODS}

\section{Chemicals and delivery apparatus}

L-(+)-Lactic acid, CAS[79-33-4], >99\% was purchased from Fluka Chemical Co. (Milwaukee, WI). A $2 \mu \mathrm{g} / \mu \mathrm{l}$ L-lactic acid stock solution was prepared in American Chemical Society (ACS) spectrophotometric grade (99\%) methanol [6756-1] (Aldrich Chemical Co., Milwaukee, WI). An aliquot of $100 \mu \mathrm{l}$ methanolic L-lactic acid stock solution (200 $\mu \mathrm{g}$ L-lactic acid) was pipetted into a plastic vial cap (15 mm inner diameter [i.d.] $\times 9.5 \mathrm{~mm}$ height, total capacity $1.4 \mathrm{ml}$ ). Prior to use, the solution was allowed to dry for at least $3 \mathrm{~min}$ to remove the methanol solvent. Methanol was chosen as the solvent because it is not attractive to Ae. aegypti in our bioassays (Bernier et al. 2001). Acetone [67-64-1] 99.5+\% ACS reagent grade and (di)methyl disulfide [624-92-0] 99\% were purchased from Aldrich Chemical Company. These 2 reagents were delivered as $400 \mu \mathrm{l}$ of neat solution each to plastic vial caps ( $9 \mathrm{~mm}$ i.d. $\times 9 \mathrm{~mm}$ height, total capacity $400 \mu \mathrm{l}$ ). In this manner, the reagents evaporated during the test at a known rate based on the surface area of the cap and compound volatility, as described previously (Bernier et al. 2003). We chose to release these chemicals in this manner because the attraction of mosquitoes to these substances has been characterized in previous work (Bernier et al. 2001, 2003). It should be noted that further optimization of the release may improve attraction, but manipulation of constituent release rates was not part of this study.

Caps containing each separate chemical were loaded immediately onto an aluminum tray constructed to hold the vials and inserted into the proper olfactometer port. When used, carbon dioxide [124-38-9] (Airgas South Inc., Gainesville, FL) was delivered from a compressed gas cylinder (Scott Specialty Gases, Plumsteadville, PA) through a fine metering valve (Nupro Co., Willoughby, $\mathrm{OH}$ ) and measured on a calibrated flowmeter set to deliver $5 \mathrm{ml} / \mathrm{min}$. This rate was selected based upon previous unpublished data by us that indicated that this rate and rates greater than this level produced the highest level of attraction response when combined with $200 \mathrm{~g}$ L-lactic acid.

\section{Laboratory bioassays}

Tests were conducted in a triple-cage dual-port olfactometer (Posey et al. 1998). Each of the 3 cages allowed for a single experiment to be conducted under known, constant conditions. During an experiment, the mosquitoes either remained in the cage or flew upwind and were captured in 1 of the 2 ports. A port contained either a treatment or control. In noncompetitive tests, the blank port contained a slow release dispenser but no treatment sample. Both the blank port and treatment ports had an identical flow of conditioned air (see below) passing through them. Provided that there is no contamination, very few mosquitoes are trapped in this control port during the course of a noncompetitive bioassay. In a competitive test, 2 treatment combinations are compared against each other. A "blank" or "control" set of apparatus is not used in this case.

The olfactometer air was drawn from outside the laboratory, then filtered, cooled or heated, 
and humidified or dehumidified as necessary by the air handling system. In the experiments reported here, the system was set to produce a constant air flow $(28 \pm 1 \mathrm{~cm} / \mathrm{sec})$ maintained at $27^{\circ} \mathrm{C} \pm 1{ }^{\circ} \mathrm{C}$ and $60 \% \pm 2 \%$ relative humidity. Approximately 75 nulliparous female (6-8 days old) Ae. aegypti were selected for each test cage from a hand draw box and a specifically designed trap (Posey and Schreck 1981) to collect the mosquitoes and load them into each of the cages. Bioassays were conducted 3 times per day (0900, 1100 , and $1300 \mathrm{~h}$ local time). Mosquitoes were loaded and allowed to acclimate in each cage of the olfactometer for 45-60 min prior to each of the bioassays. During this period, the port doors are opened slightly to allow a low flow of air to pass through the ports and into the cages. Mosquitoes were maintained in cages in the laboratory, where the ambient temperature was $27 \pm 1{ }^{\circ} \mathrm{C}$ with a $12 \mathrm{~L}: 12 \mathrm{D}$ photoperiod.

Treatments were randomized with respect to order, ports used, time of day and cage that included all noncompetitive and competitive tests. In total, 6 replicate tests were made for each treatment or treatment combination. In total, 10 treatments were used in the noncompetitive bioassays, and 11 treatment combinations (comparisons) were used in the competitive bioassays. Odors from 3 of 6 volunteers (selection of these 3 are described in the next section) were used where selection of volunteers was performed, as described below, prior to the start of this study. The mosquitoes trapped in each of the ports and those remaining in the cage were counted after each 3min bioassay. Data were recorded as a percentage of the mosquitoes attracted to each port out of the total number of mosquitoes initially in the cage. The treatments (and abbreviations) used for noncompetitive bioassays were carbon dioxide $\left(\mathrm{CO}_{2}\right)$, dimethyl disulfide (DMDS), acetone $(\mathrm{ACE})$, L-lactic acid ( $\mathrm{LA})+\mathrm{CO}_{2}, \mathrm{LA}+\mathrm{ACE}$, $\mathrm{LA}+\mathrm{DMDS}, \mathrm{LA}+\mathrm{ACE}+\mathrm{DMDS}$, and odors from the hands of 3 volunteers (subjects A, C, and F). The treatment combinations compared in competitive tests were LA+DMDS vs. DMDS, $\mathrm{LA}+\mathrm{DMDS}$ vs. LA, $\mathrm{LA}+\mathrm{ACE}$ vs. ACE, $\mathrm{LA}+\mathrm{ACE}$ vs. $\mathrm{LA}, \mathrm{LA}+\mathrm{ACE}$ vs. $\mathrm{LA}+\mathrm{CO}_{2}$, $\mathrm{LA}+\mathrm{ACE}+\mathrm{DMDS}$ vs. $\mathrm{LA}+\mathrm{CO}_{2}, \mathrm{LA}+\mathrm{A}-$ $\mathrm{CE}+\mathrm{DMDS}$ vs. $\mathrm{LA}+\mathrm{ACE}, \mathrm{LA}+\mathrm{ACE}+\mathrm{DMDS}$ vs. LA+DMDS, and odors from each of the 3 volunteers vs. $\mathrm{LA}+\mathrm{ACE}+\mathrm{DMDS}$.

\section{Selection of human subjects}

A preliminary experiment involving 6 human volunteers was performed to select 3 subjects for inclusion in the noncompetitive and competitive bioassays with compounds and blends. The subjects were chosen according to their attraction levels, such that the person who exhibited the highest mean attraction of female Ae. aegypti (subject A), the person with lowest (subject F), and the person who corresponded closest to the median attraction level (subject C) were represented. The study was accomplished over a consecutive 2-day period ( 9 tests per day), with 3 replications per individual. Treatment order, cage order, and port choice were randomized. Further, subjects were randomly selected to use either odors from the left or right hand for the study, and this remained consistent throughout all repetitions. Attraction was tested by placing the hand and arm through the sleeve of a port (the port used was assigned randomly), and the percentage of mosquitoes attracted to the port containing the treatment out of the total mosquitoes in the cage (and any captured in the control port) was counted for the 3-min test.

\section{Data analysis}

All treatment and control means were arcsine transformed before statistical analysis. The mean attraction levels of the 6 volunteers in the initial study were examined by analysis of variance (SAS Institute 1999). In the noncompetitive assays, treatment means were compared with control means by paired $t$-tests $(P<0.05)$ (SAS Institute 1999), followed by means separation with Student-Neuman-Keuls (SNK) test. In the competitive olfactometer bioassays, means were compared using paired $t$-tests $(P<0.05)$ (SAS Institute 1999).

\section{RESULTS AND DISCUSSION}

Six humans volunteered to provide arm and hand odors for this study. The levels of attraction for these subjects ( \pm standard error) were $71.3 \%$ $\pm 12.4 \%, 59.3 \% \pm 16.7 \%, 56.3 \% \pm 16.6 \%$, $50.3 \% \pm 8.2 \%, 50.0 \% \pm 24.2 \%$, and $33.0 \% \pm$ $12.5 \%$, for subjects $\mathrm{A}$ through $\mathrm{F}$, respectively. The subjects with greatest attraction (A; 71.3\%), median $(\mathrm{C} ; 56.3 \%)$, and lowest $(\mathrm{F} ; 33.0 \%)$ were selected for inclusion in the studies against the synthetic chemicals and blends. Although the subjects were ranked according to their mean attraction levels, there were no statistically significant differences between the mean attraction levels of individuals $(\mathrm{F}=0.85$; $\mathrm{df}=5,17$; $P=0.5377)$.

\section{Noncompetitive bioassays}

All treatments attracted significantly more mosquitoes than the control port (Table 1). Significant differences in attraction of mosquitoes existed between treatments $(\mathrm{F}=5.80, \mathrm{df}=9,59$; $P<0.00001)$. The treatment with the highest attraction percentage $(84.9 \%)$ was the trinary blend of L-lactic acid, acetone, and dimethyl disulfide. This was followed by the binary blend 
Table 1. Noncompetitive bioassays of treatments and comparison of the mean levels of attraction to the treatment port, the control port, and the percentage of mosquitoes that did not respond to either port.

\begin{tabular}{|c|c|c|c|}
\hline Treatment $^{1}$ & Attraction $(\% \pm \mathrm{SE})^{2}$ & Blank attraction $(\% \pm \mathrm{SE})$ & Nonresponding $(\% \pm \mathrm{SE})$ \\
\hline$\overline{\mathrm{LA}+\mathrm{ACE}+\mathrm{DMDS}}$ & $84.9 \pm 2.6^{\mathrm{a}}$ & $0.2 \pm 0.2$ & $14.9 \pm 2.1^{\mathrm{a}}$ \\
\hline $\mathrm{LA}+\mathrm{DMDS}$ & $69.4 \pm 6.9^{\mathrm{ab}}$ & $0.4 \pm 0.3$ & $30.2 \pm 7.0^{\mathrm{ab}}$ \\
\hline Subject A & $66.2 \pm 11.7^{\mathrm{ab}}$ & $0.8 \pm 0.4$ & $33.0 \pm 11.7^{\mathrm{ab}}$ \\
\hline $\mathrm{LA}+\mathrm{ACE}$ & $62.1 \pm 7.6^{\mathrm{abc}}$ & $1.1 \pm 0.4$ & $36.8 \pm 7.4^{\mathrm{abc}}$ \\
\hline Subject F & $57.3 \pm 3.8^{\mathrm{abcd}}$ & $0.5 \pm 0.3$ & $42.2 \pm 3.8^{\mathrm{abc}}$ \\
\hline $\mathrm{LA}+\mathrm{CO}_{2}$ & $36.4 \pm 14.6^{\mathrm{bcd}}$ & $1.1 \pm 0.8$ & $62.5 \pm 14.2^{\mathrm{bc}}$ \\
\hline $\mathrm{ACE}$ & $35.7 \pm 11.8^{\mathrm{bcd}}$ & $1.3 \pm 0.7$ & $63.0 \pm 11.7^{\mathrm{bc}}$ \\
\hline Subject C & $35.2 \pm 3.5^{\mathrm{bcd}}$ & $0.4 \pm 0.4$ & $64.4 \pm 10.3^{\mathrm{bc}}$ \\
\hline DMDS & $26.1 \pm 10.6^{\mathrm{cd}}$ & $2.0 \pm 1.3$ & $71.9 \pm 10.5^{\mathrm{bc}}$ \\
\hline $\mathrm{CO}_{2}$ & $14.6 \pm 10.1^{\mathrm{d}}$ & $1.8 \pm 1.1$ & $83.6 \pm 11.8^{\mathrm{c}}$ \\
\hline
\end{tabular}

${ }^{1}$ LA, L-lactic acid; ACE, acetone; DMDS, dimethyl disulfide.

${ }^{2}$ Means with the same letter in a column are not significantly different at the 0.05 level using Student-Neuman-Keuls test.

of lactic acid and dimethyl disulfide, human odors from the volunteer that routinely was the most attractive (subject A), the binary blend of lactic acid and acetone, and the human odors from subject $F$. However, the attraction levels of these 5 treatments were not significantly different at the $P$ $=0.05$ level. Odors from all 3 volunteers; the binary blends of lactic acid with either dimethyl disulfide, acetone, or carbon dioxide; and the single component acetone attracted mosquitoes at levels that were not significantly different. The odors from subjects $\mathrm{C}$ and $\mathrm{F}$, the binary blends of lactic acid plus acetone and lactic acid plus carbon dioxide, and the single components acetone and dimethyl disulfide attracted mosquitoes at levels that were statistically different in this series of noncompetitive bioassays.

The distribution and statistical breakdown of the percentage of nonresponding mosquitoes remaining in the cage (those not collected in either port) was nearly identical to that of the attractants. Specifically, there were no significant differences in the collection of mosquitoes in the treatment ports for the 5 most attractive treatments, nor were there differences in the percentages of nonresponders. The least potent attractant in this study is carbon dioxide alone. We believe that $\mathrm{CO}_{2}$ in the absence of other odors is at best a weak attractant. Its role is much more significant as a synergist, primer, or sensitizer, when combined with other odors (Dekker et al. 2005). The most potent attractant, in terms of the percentage of mosquitoes collected in the treatment port, is the trinary blend. Therefore, this was our most promising blend to test further by pitting it in competition against human odors and other known attractant blends.

\section{Competitive bioassays}

Individual A attracted a much higher percentage of the mosquitoes $(70.7 \%)$ than did the 3compound blend $(14.3 \%)(P<0.001$; Table 2).
This treatment combination resulted in the lowest percentage of mosquitoes remaining in the cage (15\% nonresponders). This may corroborate results from the noncompetitive bioassays since these 2 treatments are the 2 most potent attractants in these assays. Subject $\mathrm{C}$ attracted $60 \%$ of the mosquitoes, compared with $23.7 \%$ for the blend, and subject $F$ attracted $45.4 \%$ of the mosquitoes, while the blend trapped $29.7 \%$. In both cases, human odors attracted a significantly greater percentage of mosquitoes than did the trinary blend. Examination of the nonaveraged (raw) data for the competitive tests showed that subject A collected the majority of mosquitoes in all 6 repetitions. Odors from subject $\mathrm{C}$ collected more mosquitoes than the blend in 4 of 6 repetitions, while odors from subject $F$ were more attractive in 3 repetitions, with 1 repetition having an exact tie, where $37.7 \%$ of the mosquitoes were attracted to each treatment.

The next 3 treatment combinations in Table 2 compared attraction of the trinary blend with 2 binary blends (that were subsets of compounds from the trinary blend) and to the classic binary combination of lactic acid plus carbon dioxide (Smith et al. 1970). The trinary blend was significantly more attractive than either lactic acid plus acetone or lactic acid plus carbon dioxide; however, was not significantly greater when compared with the blend of lactic acid plus dimethyl disulfide. The results were, however, fairly consistent with those reported previously (Bernier et al. 2001).

As shown in the third section of Table 2, the binary blend of lactic acid and acetone was significantly more attractive than the lactic acid and carbon dioxide combination, lactic acid alone, and acetone alone. The binary blend of lactic acid and dimethyl disulfide, when tested against its single constituents, was significantly more attractive than lactic acid alone and dimethyl disulfide alone. This was expected, also, since synergism has been established for these 
Table 2. Percentage of mosquitoes attracted and nonresponding in competitive bioassays of chemicals and human odors. Treatment means were compared by paired $t$-tests $(P<0.05)$.

\begin{tabular}{|c|c|c|c|}
\hline Compared treatments ${ }^{1}$ & Attraction $(\% \pm \mathrm{SE})$ & $t^{2}$ & Nonresponding $(\% \pm \mathrm{SE})$ \\
\hline Subject A & $70.7 \pm 8.1$ & $6.35 * *$ & $15.0 \pm 5.7$ \\
\hline $\mathrm{LA}+\mathrm{ACE}+\mathrm{DMDS}$ & $14.3 \pm 3.4$ & & \\
\hline Subject C & $60.0 \pm 10.0$ & $2.84^{*}$ & $16.3 \pm 4.7$ \\
\hline $\mathrm{LA}+\mathrm{ACE}+\mathrm{DMDS}$ & $23.7 \pm 7.7$ & & \\
\hline Subject F & $45.4 \pm 4.1$ & $1.93^{*}$ & $24.9 \pm 4.1$ \\
\hline $\mathrm{LA}+\mathrm{ACE}+\mathrm{DMDS}$ & $29.7 \pm 6.7$ & & \\
\hline $\mathrm{LA}+\mathrm{ACE}+\mathrm{DMDS}$ & $53.1 \pm 10.0$ & $3.29 * *$ & $27.3 \pm 11.9$ \\
\hline $\mathrm{LA}+\mathrm{ACE}$ & $19.6 \pm 4.5$ & & \\
\hline $\mathrm{LA}+\mathrm{ACE}+\mathrm{DMDS}$ & $45.9 \pm 6.3$ & $1.87^{*}$ & $27.0 \pm 6.9$ \\
\hline $\mathrm{LA}+\mathrm{CO}_{2}$ & $27.1 \pm 8.3$ & & \\
\hline $\mathrm{LA}+\mathrm{ACE}+\mathrm{DMDS}$ & $42.0 \pm 7.5$ & $1.50 \mathrm{~ns}$ & $29.1 \pm 8.0$ \\
\hline $\mathrm{LA}+\mathrm{DMDS}$ & $28.9 \pm 4.1$ & & \\
\hline $\mathrm{LA}+\mathrm{ACE}$ & $62.7 \pm 9.7$ & $5.46^{* *}$ & $30.4 \pm 7.1$ \\
\hline $\mathrm{LA}+\mathrm{CO}_{2}$ & $6.9 \pm 4.1$ & & \\
\hline $\mathrm{LA}+\mathrm{ACE}$ & $56.6 \pm 11.3$ & $2.12 *$ & $38.6 \pm 11.7$ \\
\hline LA & $4.8 \pm 2.1$ & & \\
\hline $\mathrm{LA}+\mathrm{ACE}$ & $53.9 \pm 7.3$ & $6.23 * *$ & $29.8 \pm 6.4$ \\
\hline $\mathrm{ACE}$ & $16.2 \pm 3.4$ & & \\
\hline $\mathrm{LA}+\mathrm{DMDS}$ & $56.0 \pm 12.1$ & $3.21 *$ & $28.9 \pm 12.7$ \\
\hline LA & $15.1 \pm 5.0$ & & \\
\hline $\mathrm{LA}+\mathrm{DMDS}$ & $53.9 \pm 6.7$ & $6.23 * *$ & $34.2 \pm 6.6$ \\
\hline DMDS & $11.9 \pm 2.5$ & & \\
\hline
\end{tabular}

$* 0.001<P<0.05$.

** $P<0.001$.

${ }^{1}$ LA, L-lactic acid; ACE, acetone; DMDS, dimethyl disulfide.

${ }^{2}$ ns, no significant difference.

blends of acetone and dimethyl disulfide with lactic acid (Bernier et al. 2003).

An interesting trend is noticeable with the percentage of nonresponding mosquitoes when comparing the 3 sections of Table 2. Specifically, tests with human odors and the more potent blends result in fewer nonresponding mosquitoes left in the cage, i.e., $15.0-24.9 \%$ left for the 3 treatment combinations in the top section of Table 2. Potent blends tested against each other are found in the middle section of the table, and these result in a range of 27.0-29.1\% nonresponding mosquitoes. In the bottom section of the table, the blends and single component paired tests result in $28.9-34.2 \%$ of the mosquitoes nonresponding to either treatment. These results are indicative of the potency of the combinations employed. Therefore, one would expect that had subjects A and B been tested simultaneously in this study, or any odors from humans for that matter, the resultant percentage of nonresponding mosquitoes would be $<15.0 \%$. A previous study that corroborates this finding (Kline et al. 2003) tested a human odor blend comprised of shaved human facial hair in acetone in competitive assays with this same dual-port olfactometer. This resulted in approximately $7 \%$ of the mosquitoes remaining in the cage.

This study indicates that 1) blends produce high levels of attraction without employing carbon dioxide; 2) in general, the trinary blend is more attractive to these mosquitoes than the binary blends; 3 ) the trinary blend approaches the attraction potency of some humans; and 4) further blend development, either by adjustment of blend composition or, more likely, by addition of another compound will be necessary to make a synthetic blend more competitive against human odors.

\section{REFERENCES CITED}

Acree F Jr, Turner RB, Gouck HK, Beroza M. 1968. L-Lactic acid: a mosquito attractant isolated from humans. Science 161:1346-1347.

Bernier UR. 2006. Laboratory research and development of attractants, inhibitors and repellents. Tech Bull Florida Mosq Control Assoc 7:9-16.

Bernier UR, Booth MM, Yost RA. 1999. Analysis of human skin emanations by gas chromatography/mass spectrometry. 1. Thermal desorption of attractants for the yellow fever mosquito (Aedes aegypti) from handled glass beads. Anal Chem 71:1-7.

Bernier UR, Kline DL, Barnard DR, Posey KH, Booth MM, Yost RA. 2001. Chemical composition that attracts arthropods. US Patent No. 6,267,953. U.S. Patent and Trademark Office, Washington, DC.

Bernier UR, Kline DL, Barnard DR, Schreck CE, Yost RA. 2000. Analysis of human skin emanations by gas chromatography/mass spectrometry. 2. Identification of volatile compounds that are candidate attractants for the yellow fever mosquito (Aedes aegypti). Anal Chem 72:747-756. 
Bernier UR, Kline DL, Posey KH, Booth MM, Yost RA, Barnard DR. 2003. Synergistic attraction of Aedes aegypti (L.) to binary blends of L-lactic acid and acetone, dichloromethane, or dimethyl disulfide. $J$ Med Entomol 40:653-656.

Bernier UR, Kline DL, Schreck CE, Yost RA, Barnard DR. 2002. Chemical analysis of human skin emanations: comparison of volatiles from humans that differ in attraction of Aedes aegypti (Diptera: Culicidae). J Am Mosq Control Assoc 18:186-195.

Bosch OJ, Geier M, Boeckh J. 2000. Contribution of fatty acids to olfactory host finding of female Aedes aegypti. Chem Senses 25:323-330.

Conkle JP, Mabson WE, Adams JD, Zeft HJ, Welch BE. 1967. Detailed study of contaminant production in a space cabin simulator at $760 \mathrm{~mm}$ of mercury. Aerospace Med 38:491-499.

Cork A, Park KC. 1996. Identification of electrophysiologically-active compounds for the malaria mosquito Anopheles gambiae in human sweat extracts. Med Vet Entomol 10:269-276.

Dekker T, Geier M, Cardé RT. 2005. Carbon dioxide instantly sensitizes female yellow fever mosquitoes to human skin odors. J Exp Biol 208:2963-2972.

Dekker T, Steib B, Cardé RT, Geier M. 2002. L-Lactic acid: a human-signifying host cue for the anthropophilic mosquito Anopheles gambiae. Med Vet Entomol 16:91-98.

Ellin RI, Farrand RL, Oberst FW, Crouse CL, Billups NB, Koon WS, Musselman NP, Sidell FR. 1974. An apparatus for the detection and quantitation of volatile human effluents. J Chromatogr 100:137-152.

Geier M, Bosch OJ, Boeckh J. 1999a. Influence of odour plumes on upwind flight of mosquitoes towards hosts. J Exp Biol 202:1639-1648.

Geier M, Bosch OJ, Boeckh J. 1999b. Ammonia as an attractive component of host odour for the yellow fever mosquito, Aedes aegypti. Chem. Senses 24: 647-653.

Geier M, Sass H, Boeckh J. 1996. A search for components in human body odour that attract females of Aedes aegypti. In: Bock GR, Cardew G, eds. Olfaction in mosquito-host interactions. London, United Kingdom: Ciba Foundation. p 132-148.

Gillies MT. 1980. The role of carbon dioxide in hostfinding by mosquitoes (Diptera: Culicidae): a review. Bull Ent Res 70:525-532.

Kline DL, Bernier UR, Posey KH, Barnard DR. 2003. Olfactometric evaluation of spatial repellents for Aedes aegypti. J Med Entomol 40:463-467.

Kline DL, Dame DA, Meisch MV. 1991a. Evaluation of 1-octen-3-ol and carbon dioxide as attractants for mosquitoes associated with irrigated rice fields in Arkansas. J Am Mosq Control Assoc 7:165-169.

Kline DL, Takken W, Wood JR, Carlson DA. 1990. Field studies on the potential of butanone, carbon dioxide, honey extract, 1-octen-3-ol, L-lactic acid and phenols as attractants for mosquitoes. Med Vet Entomol 4:383-391.

Kline DL, Wood JR, Cornell JA. 1991b. Interactive effects of 1-octen-3-ol and carbon dioxide on mosquito (Diptera: Culicidae) surveillance and control. J Med Entomol 28:254-258.

Mukabana WR, Takken W, Killeen GF, Knols BGJ. 2004. Allomonal effect of breath contributes to differential attractiveness of humans to the African malaria vector Anopheles gambiae. Malar $J$ [Internet] 3:1. [accessed June 11, 2007]. Available from: http:// www.malariajournal.com/content/3/1/1.

Posey KH, Barnard DR, Schreck CE. 1998. Triple cage olfactometer for evaluating mosquito (Diptera: $\mathrm{Cu}$ licidae) attraction responses. $J$ Med Entomol 35: 330-334

Posey KH, Schreck CE. 1981. An airflow apparatus for selecting female mosquitoes for use in repellent and attraction studies. Mosq News 41:566-568.

SAS Institute. 1999. SAS/STAT User's Guide, version 8. Cary, NC: SAS Institute.

Sastry SD, Buck KT, Janák J, Dressler M, Preti G. 1980. Volatiles emitted by humans, In: Waller GR, Dermer OC, eds. Biochemical applications of mass spectrometery. First supplementary volume. Chichester, England: John Wiley \& Sons. p 1085-1129.

Schreck CE, Kline DL, Carlson DA. 1990. Mosquito attraction to substances from the skin of different humans. J Am Mosq Control Assoc 6:406-410.

Schreck CE, Smith N, Carlson DA, Price GD, Haile D, Godwin DR. 1981. A material isolated from human hands that attracts female mosquitoes. $J$ Chem Ecol 8:429-438.

Smith CN, Smith N, Gouck HK, Weidhaas DE, Gilbert IH, Mayer MS, Smittle BJ, Hofbauer A. 1970. L-lactic acid as a factor in the attraction of Aedes aegypti (Diptera: Culicidae) to human hosts. Ann Entomol Soc Am 63:760-770.

Takken W. 1991. The role of olfaction in host-seeking of mosquitoes: a review. Insect Sci Appl 12:287-295.

Takken W, Dekker T, Wijnolds TG. 1997. Odormediated flight behavior of Anopheles gambiae Giles sensu stricto and An. stephensi Liston in response to $\mathrm{CO}_{2}$, acetone, and 1-octen-3-ol (Diptera: Culicidae). J Insect Behav 10:395-407.

Takken W, Kline DL. 1989. Carbon dioxide and 1octen-3-ol as mosquito attractants. $J$ Am Mosq Control Assoc 5:311-316.

Takken W, Knols BGJ. 1999. Odor-mediated behavior of Afrotropical malaria mosquitoes. Annu Rev Entomol 44:131-157.

Williams CR, Bergbauer R, Geier M, Kline DL, Bernier UR, Russell RC, Ritchie SA. 2006. Laboratory and field assessment of some kairomone blends for hostseeking Aedes aegypti. J Am Mosq Control Assoc 22:641-647.

Wysocki CJ, Preti G. 2000. Human body odors and their perception. Jpn J Taste Smell Res 7:19-42.

Zeng X-N, Leyden JJ, Brand JG, Spielman AI, McGinley KJ, Preti G. 1992. An investigation of human apocrine gland secretion for axillary odor precursors. J Chem Ecol 18:1039-1055.

Zeng X-N, Leyden JJ, Lawley HJ, Sawano K, Nohara I, Preti G. 1991. Analysis of characteristic odors from human male axillae. J Chem Ecol 17:1469-1492. 